University of Tennessee Health Science Center UTHSC Digital Commons

Summer 7-9-2020

\title{
Computer-Assisted Coding: Post ICD-10 Implementation
}

Teresa C. Allen

University of Tennessee Health Science Center

Follow this and additional works at: https://dc.uthsc.edu/hiimappliedresearch

Part of the Health and Medical Administration Commons, and the Health Information Technology Commons

\section{Recommended Citation}

Allen, Teresa C., "Computer-Assisted Coding: Post ICD-10 Implementation" (2020). Applied Research Projects. 70. . https://doi.org/10.21007/chp.hiim.0068

https://dc.uthsc.edu/hiimappliedresearch/70

This Research Project is brought to you for free and open access by the Department of Health Informatics and Information Management at UTHSC Digital Commons. It has been accepted for inclusion in Applied Research Projects by an authorized administrator of UTHSC Digital Commons. For more information, please contact jwelch30@uthsc.edu. 
Running head: COMPUTER-ASSISTED

\section{Computer-Assisted Coding: Post ICD-10 Implementation}

Teresa Caroline Allen, RHIA

Department of Diagnostic and Health Sciences

Advisor: Sajeesh Kumar, Ph. D

This study has been approved by the University of Tennessee Health Science

Center IRB \# - 20-07199-XM Approval Date - April 1, 2020

August 2020 


\begin{abstract}
Computer-assisted coding (CAC) has been around since the 1950 s and is projecting to reach $\$ 4.75$ Billion by 2022 . However, it has not been on the hospitals' priority list until 2014 before the implementation of ICD-10 in 2015. Computer-assisted coding is a technology software that helps streamline the coding workflow, reduce backlogs by increasing productivity, and help coders navigate through more extended, more complex charts more quickly. The technology is a type of artificial intelligence. The idea of computer-assisted became more front-line with the implementation of electronic health records (EHRs) and the demands of a more restrictive reimbursement from payers. Accuracy, consistency, and, most assuredly, productivity has been of great importance to all organizations. Due to the increase in advanced technologies, computer-assisted coding has advanced in its performance. However, the question remains as to if it has lived up to the recent hype before the implementation of ICD-10 to increase productivity, accuracy, consistency, improve clinical documentation, etc. This study was conducted using a questionnaire to survey the Tennessee Health Information Management (THIMA) community members as to the effectiveness of computer-assisted coding five years after the implementation of ICD-10. The results of the survey show that there are organizations that are still not using CAC. The overall perception of the respondents feel CAC is not a must-have technology to code efficiently but, with the CAC, the overall coding process is satisfactory but still needs improvement.
\end{abstract}

Keywords: computer-assisted coding, automated clinical coding, clinical coding, statistics collected about computer-assisted coding, problems associated with CAC 


\section{Table of Contents}

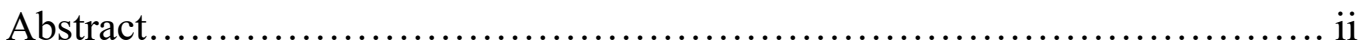

Table of Contents...................................................... ii

Table of Contents................................................ iv

List of Tables........................................................

List of Figures......................................................

Chapter One...................................................................1

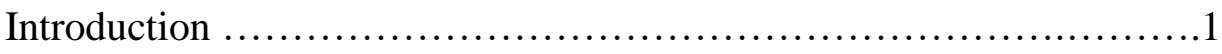

Background of the Problem...................................... 3

Purpose and Significance of the Study............................4

Theoretical Framework.........................................5

Research Questions...........................................6

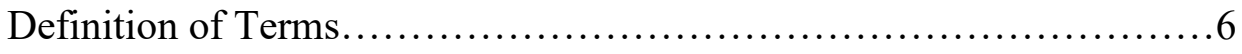

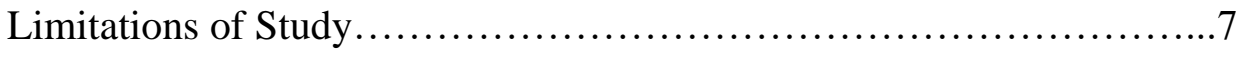

Chapter Two................................................................9

Review of Literature......................................... 9

Background of CAC ........................................9

Chapter Three.....................................................................10

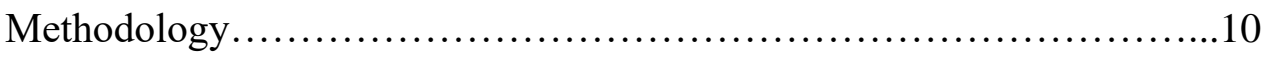

Research Design.............................................10

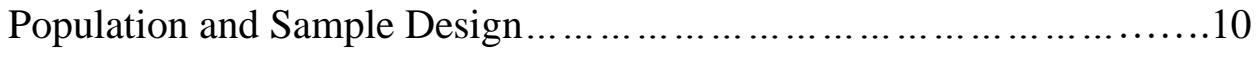

Data Collection Procedures........................................11

Data Collection Instrument....................................11 
Data Analysis.................................................. 12

Response Rate..............................................12

Research Questions..........................................12

Summary of Chapter..........................................13

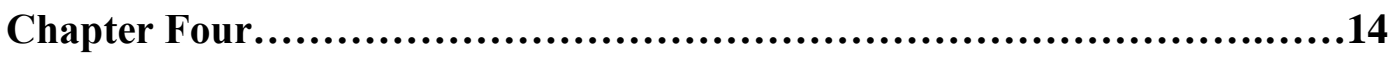

Results...................................................... 14

Response Rate of Sample/Population.............................14

Profile of Sample/Population.................................... 14

Results of Research Questions..................................14

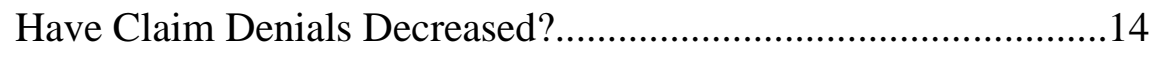

Has consistency and accuracy rates improved?..........................15

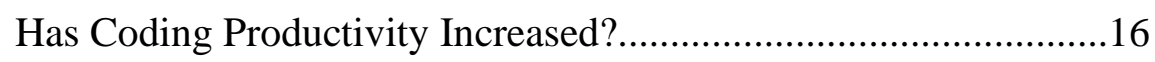

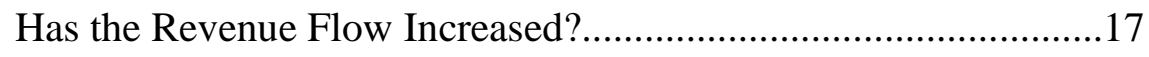

Has CAC Resulted in Decreasing the Number of Coders?............18

Has the Overall Coding Process Improved with CAC?................19

Has Clinical Documentation Improved Since CAC?...................20

Is It Coders' Perspective that CAC Has Improved Coding?..........20

Is CAC a Must-Have Coding Software for Facilities?..................21

Coders' Profile Population.................................22

Job Title........................................23

AHIMA Credentials....................................24

Years of Coding Experience...........................25

Years of CAC Experience............................26 
COMPUTER-ASSISTED CODING

Summary of Chapter........................................27

Chapter 5 ....................................................................28

Summary of Findings........................................28

Conclusions...................................................28

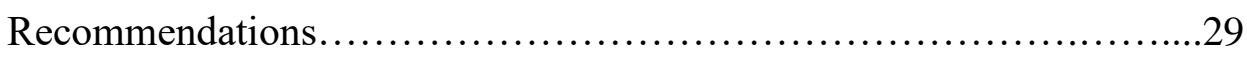

References.............................................................

Table

Table 1 - Profile Experience of Respondents............................22

\section{List of Figures}

Graph 1 - Claim Denials............................................15

Graph 2 - Consistency and Accuracy Rates............................16

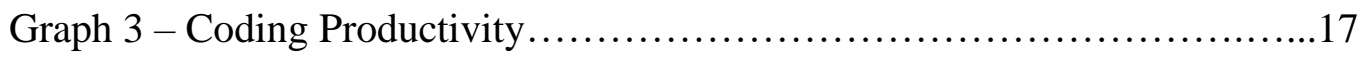

Graph 4 - Revenue Flow.........................................18

Graph 5 - Full-Time Coder Equivalents................................19

Graph 6 - Overall Coding Process.................................... 19

Graph 7 - Clinical Documentation Improvement.......................20

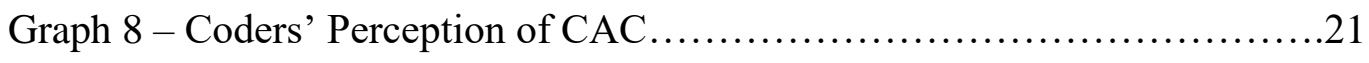

Graph 9 - CAC Must-Have for Facilities.............................22

\section{Appendix A}

Consent Form .................................................... 33

\section{Appendix B}

Research Questions.................................................. 35 
COMPUTER-ASSISTED CODING

\section{Chapter 1}

\section{Introduction}

Information technology has improved the workflow in all aspects of healthcare within various organizations. The implementation of the electronic health record (EHR) and the electronic medical record (EMR) paved the road to introducing more technology and computerized tools with natural language processing (NLP) and artificial intelligence (AI) that has the capability of enhancing communications between machines and humans. Before the implementation of the electronic health record (EHR), medical coders translated handwritten clinical documentation into ICD-9 or CPT/HCPCS codes. After analysing a chart and determining the clinical diagnoses and procedures to be coded, medical coders use codebooks and encoders as the method of assigning these codes. Over the years, as more stipulations were put on correct coding initiatives, came the need, some believed, to give computer-assisted coding a try. The implementation of prospective payment systems, and the need to increase productivity, put pressure on organizations to look for something that would produce faster and better coding accuracy. The shortage of HIM-educated and certified coding professionals, along with the transition to ICD-10, also played a part in facilities looking for ways that fewer coders could get the job done. As technology has advanced, healthcare roles and the working environment for many healthcare professionals have had to adjust thrive in the changing work environment. The movement to adopt EHRs and create a national health information infrastructure began even more so the advancement of computer-assisted coding along with many other advanced technologies. The innovative adoption of EHRs, artificial intelligence (AI), and natural language processing (NLP) contributes to the changing role of a medical coder. 


\section{COMPUTER-ASSISTED CODING}

From the technologies mentioned above, computer-assisted coding (CAC) continued to develop and has changed the role of professional medical coders. The image below provides the timeline enabling computer-assisted coding. In the beginning, the idea of a CAC brought unnecessary concern that medical coders were going to be out of a job due to this new innovative CAC. The results of the survey for this research will provide the coder's current perspective about the use of the CAC. A negative mindset from both coders and hospitals created obstacles for the adoption of the CAC. Computer-assisted coding was not a priority technology. It had minimal data to compare on the return of investment, and the implementation process was perceived to be very complicated. Limitations on the types of clinical settings in which the CAC could be useful and staff replacement were some of the obstacles that hindered the adoption of the CAC (Covit, n.d.).

The innovation of the CAC with the natural language processing began more than 25 years ago but never really took hold or began to be promoted until it was perceived that the United States would be officially transitioning from the ICD-9 to ICD-10 coding classification. Even with all the other necessities of needing CAC as mentioned above, it was not until the sincerity of adopting ICD-10 came about that organizations started looking at computer-assisted coding to alleviate potential drop in productivity that would lead to the decline of revenue. The move to adopt ICD-10 as the official coding classification for the United States was the opportunity that CAC needed to advance the technology and contribute to allowing for a smoother transition to ICD-10. Before this and due to the ICD-9 classification being the official coding classification for the United States for 30 years, and everyone was well versed with this classification, there was no 


\section{COMPUTER-ASSISTED CODING}

interest in adopting new technology for coding purposes. The use of CAC before the implementation of ICD-10 and the capabilities of the CAC was not advanced enough to handle the more complicated medical notes. Instead, being used to code the more straightforward records such as routine mammograms, chest x-rays, and x-rays of fractures (Schnitzer, 2008).

Computer-assisted coding is a computerized software tool that reads and analyses clinical documentation and automatically generates medical codes to be reviewed and validated based on clinical documentation provided by physicians and other healthcare professionals. Computer-assisted coding accomplishes this process by using natural language processes for free text documentation and structured input using menus that contain clinical terms. The NLP processing software technology uses artificial intelligence to extract data and phrases from a text-based document and converts them into a set of medical codes to be used or edited by a coding professional (AHIMA e-HIM Workgroup, 2004). (Figure 2). The NLP allows physicians to document using their preferred terms. For the structured input, codes are embedded into the system, and a physician chooses a populated narrative text phrase from a menu item. The system assigns the code associated with the issue the physician selected, and then the code can be accepted, modified, or rejected by the coder based on the clinical documentation.

\section{Background of Problem}

When the United States switched from the 30-year-old ICD-9 coding classification to ICD-10, there were concerns as to how this transition would affect the overall healthcare system. Even though computer-assisted coding (CAC) has been around for many years and has been used to some extent, it just recently, with the 


\section{COMPUTER-ASSISTED CODING}

implementation ICD-10 in 2015, became the focus of attention with the CAC being publicized as the answer to several systemic issues like coder productivity, quality of coding, financial protection with less revenue loss, along with claim denials and clinical documentation issues., With the new ICD-10 coding system being implemented, there were concerns with decreased productivity, accuracy rate dropping, consistency with coding, disruption of workflow, denied claims, revenue loss, documentation challenges, drop-in clinician productivity, loss of coding positions, and the lists continues with predictions of how the transition to ICD-10 coding would negatively impact the workflow of healthcare services. At the initial transition to ICD-10 in 2015, it was expected to see somewhat of a drop in revenue, productivity, etc., until everything settled down and everyone's worries were put to ease.

\section{The Purpose and Significance of the Study}

The purpose of this study is to determine, after approximately five years of using the new ICD-10 classification for clinical coding if computer-assisted coding has lived up to the hype as previously publicized. The computer-assisted coding was persuasively marketed for adoption, before the implementation of ICD-10, to help healthcare organizations with consistent, accuracy, and proficiency with coding, increase coding productivity, reduce claim denials, assist with improving clinical documentation, reduced the number of full-time equivalents, therefore, reducing coding costs, and provide the organization with a smoother transition to ICD-10. The purpose of this study is to hopefully provide feedback and share the latest statistics about the use of computerassisted coding. For this study, a survey will be posted on the THIMA community to gather data as to whether organizations agree or disagree as to whether or not computer- 


\section{COMPUTER-ASSISTED CODING}

assisted coding has lived up the hype and met the criteria that have been expected and advertised.

According to Mary Butler from the Journal of AHIMA, market research has anticipated a spike in CAC to reach $\$ 5.1$ billion by 2023 . The article also asked the question if facilities with CAC are better off with facilities without CAC. A lot of revenue is spent on technology, and research is needed to show the statistics on whether certain technologies are essential to the success of an organization. The difference between having technology out of necessity versus it being a luxury should be researched by organizations looking for ways to improve their revenue flow. Statistics should be available to help organizations make those crucial decisions.

\section{Theoretical Framework}

This study is not intended to be based on a previous model of computer-assisted coding study cases but rather is designed on confirming if CAC has lived up to the hype of being an essential tool to improve coding productivity, accuracy, etc., after the implementation of ICD-10 as previously indicated. The information collected from this research is intended to provide current data from HIM professionals working with or managing CAC to hopefully help determine if CAC is an essential tool or software that organizations should invest in for the coming years. In theory, past studies have shown that CAC has improved the overall coding process, and most of the data indicated a positive review of using CAC. 


\section{COMPUTER-ASSISTED CODING}

\section{Research Questions}

The specific questions asked on this research survey were performed using Survey Monkey and a Likert Scale. The statistical analysis of this survey is conveyed by using a bar chart to indicate the percentage of the total number of responses given for each answer showing the highest to the lowest portion of the responders' answers. For the questions that have two objectives to answer within one item, the multiple-choice answers addressed each purpose. The questions also indicate that the questions should be answered post-ICD-10 implementation. The objectives of this study were to answer questions:

Has CAC prevented the loss of revenue with the transition to ICD-10?

Has CAC prevented the loss of productivity with the transition to ICD-10?

Has CAC helped sustained consistency and accuracy with coding?

Has CAC affected the number of coders needed for organizations?

Has CAC contributed to improving clinical documentation?

How well do the coders accept CAC at their organizations?

Is CAC a must-have for organizations to perform efficiently?

\section{Definition of Terms}

AHIMA credential - refers to the qualification, achievement, personal quality of a person's background, and any certification to indicate they are suitable to perform a job. The AHIMA credential was collected for this survey to determine if the data collected is from a person that would know CAC.

Claim denials - is the refusal of a third-party payer to pay for healthcare services obtained from a health care professional. A lot of claim denials inhibit steady revenue flowing into an organization or physician office.

Clinical document improvement (CDI) - in this setting, CDI refers to how well physicians document patient information in the chart for the coding process that results in detailed specific coding of diagnoses and procedures without coders querying the 


\section{COMPUTER-ASSISTED CODING}

physicians more than not because of incomplete documentation. Documentation supports the coding.

Coders - This is referring to HIM professionals with a coding credential that is qualified to assign diagnosis and procedure codes from the physician documentation within a chart.

Coder accuracy rate - accurately coding diagnosis and procedures to ensure the proper billing and reimbursement to the physician or facility. Inaccurate coding has a negative impact on revenue.

Coder consistency - coders, are reliable to assign accurate codes consistently

Coder productivity - number of charts coded by each coder within a specific timeframe based on facility standards.

The coding process - describes the coding cycle from beginning to end, including documentation, accuracy in coding, revenue flow, querying, discharged not final billed, etc.

Computer-assisted coding (CAC) - is software that analyses healthcare documents and procedures and automatically assigns medical codes for specific terms and phrases within the document. This survey does not question whether the CAC used natural language processing (NLP) or structured input (SI).

Full-time equivalents (FTE) - in this setting, FTE's refers to the number of coders a facility employs.

ICD-10-CM - International Classification of Diseases- $10^{\text {th }}$ Revision-Clinical Modification. The United States (US) clinical modification of the World Health Organization's ICD-10 developed to support US health information needs. They are designed for classifying and reporting diseases in all US healthcare settings.

Job title - refers to the current job title of the person participating in the survey.

Responder - This is referring to one of the seventy-five persons taking the survey.

Revenue flow - revenue flow in this setting pertains to the consistency of revenue flowing into an organization that is not hindered from inaccurate coding and claim denials.

\section{Limitations of This Study}

The sample population for this study will be obtained only from the Tennessee Health Information Management (THIMA) members; therefore, the sample may be too 


\section{COMPUTER-ASSISTED CODING}

small or not sufficient to make a significant decision about CAC. The answers on the survey will be limited to making a choice that might not completely answer the question leaving the surveyor to choose from the list that may not represent the views of the surveyor as accurate as it could be. Due to using the free subscription of the Monkey Survey, questions were limited to ten items, not allowing the opportunity to ask enough questions to provide a more detailed study about CAC. Time does not permit us to do indepth research by going to different facilities and looking at data or personally interviewing organizations concerning the outcomes of the computer-assisted coding to get a better overview of the perception of the computer-assisted coding. One of the multiple-choice answers is “don't know," meaning the responder does not know the answer to the question because they do not have access to that information. They are not able to see how an organization is performing to answer the question. The respondents may have multiple years of experience with coding but very few years of experience, if any, with CAC. 


\section{Chapter 2}

\section{Review of the Literature}

A literature review was performed by researching articles about computer-assisted coding, looking at the expected results that organizations should experience according to the literature reviews, and previous data collected about CAC. Keywords used were computer-assisted coding, automated clinical coding, clinical coding, statistics collected about computer-assisted coding, problems associated with computer-assisted coding, etc. A total of 27 articles were reviewed, and 17 were used in this research. The literature review revealed mixed experiences and thoughts about the success of CAC. Hopefully, enough information can be collected to determine if computer-assisted coding has lived up to the hype and should be considered for use in the future that would justify purchasing the software. Is this software needed to protect the revenue flow for organizations?

\section{Background of CAC}

$\mathrm{CAC}$ is an emerging technology that uses natural language processing or structured input to generate diagnosis and procedure codes from clinical documentation automatically. CAC intends to increase productivity, reduce coding errors, and make the overall coding process a better experience, especially with the transition to ICD-10. The technology for CAC has improved over the years but still needs improvement to assist with the more complex charts.

Methods used to research, and the findings are presented here. 


\section{Chapter 3}

\section{Methodology}

The methods used to recruit participants, collect data, and an explanation as to how the material was collected, distributed, and analyzed for this study.

\section{Research Design}

A literature review was performed using the Journal of AHIMA, AHIMA Body of Knowledge, PubMed, MiraMed, HIT Consultant, ICD10 Monitor, HCPro, Perspectives Health Information Management, and Google Scholar. A research librarian at the University of Tennessee Health Science Center was consulted to assist in a thorough search of relevant articles. The research was conducted using combinations of key terms such as computer-assisted coding, the hype of computer-assisted coding, data collected about computer-assisted coding, computer-assisted coding statistics, marketing, and studies.

Articles used were written from 2004 to 2019 to capture data from studies that have happened over the past ten years, especially since 2015 and the implementation of ICD-10. This research does not specify between inpatient or outpatient charts but rather only the performance of CAC.

\section{Population and Sample Design}

A questionnaire was created to obtain data from individuals, members of the Tennessee Health Information Management Association (THIMA) of the population. A sample size of 50 to 100 people was expected, with the results of responders being 75 . A large sample size of individuals with experience or knowledge of CAC is needed.

\section{Data Collection Procedures}




\section{COMPUTER-ASSISTED CODING}

To know what questions were relevant to use on my survey, it was necessary to research various articles to focus on the main objectives of what CAC vendors and other organizations were saying about CAC. Data was gathered from multiple reports to format the survey questions based on the assured outcomes of CAC. After identifying what questions should be asked, ten questions were developed using Survey Monkey creating a Likert Scale with various formats of multiple-choice answers to best answer the questions. Data was gathered by posting a closed-ended questionnaire (Appendix B) survey on the Tennessee Health Information Management Association (THIMA) community site. The survey was open for approximately three weeks. The Survey Monkey software was used to analyze the data and form bar charts to provide visual graphs of the data and providing the percentage of responders' responses for each answer to each question.

THIMA has a membership of approximately 2,600 members with seven local associations: Chattanooga, Knoxville, Memphis, Middle TN, Mid-East, Upper-East, and West, TN. THIMA is a component state association of the American Health Information Management Association (AHIMA).

\section{Data Collection Instrument}

The research instrument used for this research project was a survey questionnaire that was created using Survey Monkey. A Likert Scale that consists of nine closed-ended questions with multiple-choice answers and one open-ended question was used. The open question requested the number of years of experience the respondent had with CAC, the number of years the respondent has been coding, and asked the respondent to list AHIMA credentials, if any. 


\section{COMPUTER-ASSISTED CODING}

\section{Data Analysis}

Data analysis will be performed using the Survey Monkey software. Data will be collected for each question, and the responses for each question will be calculated.

\section{Response Rate}

The number of participates is estimated to be between 50-100.

\section{Research Questions}

Questions were formulated from information gathered from the literature review based on the criteria that CAC vendors were inferring that would prevent a reduction in production, revenue, promote consistency and accuracy with coding during the transition period from going from ICD-9 coding to ICD-10.

The following is a list of the questions on the questionnaire survey: (also, see Appendix B).

1. Have claims denials increased, decreased, has had no significant change, or the responder did not know?

2. Has the accuracy and consistency rates increased, decreased, has had no significant change, and or the responder did not know?

3. Has productivity increased, decreased, has had no significant change or, the responder did not know.

4. Has the current revenue flow increase, decreased, has had no significant change, the responder did not know, or whether the facility used CAC?

5. Has the coding cost or number of coders increased, decreased, has had no significant change or the responder did not know?

6. Is the overall coding process satisfactory, not satisfactory, is satisfactory but still needs improvement, is not satisfactory and needs much improvement or the responder did not know?

7. Has CAC contributed to the improvement of clinical documentation, or has it had no significant improvement in clinical documentation, some 


\section{COMPUTER-ASSISTED CODING}

improvements but still needs work, no improvements at all, or the responder did not know?

8. Do coders feel that CAC has improved the accuracy of their coding, improved the consistency of their coding, has had no effect on their coding, or has it hindered their coding, does not like CAC, or the responder did not know?

9. Is CAC a must for a facility to perform efficiently with their coding, yes, no, undecided, or the responder did not know?

10. The responders were asked to provide their job title, AHIMA credentials, if any, and the number of years of experience with CAC/coding.

\section{Summary of Chapter}

A survey questionnaire will be posted to the THIMA community to collect data about the use of CAC after the implementation of ICD-10. The results of the data collected will be calculated and analyzed to provide the percentages of each responders' response.

\section{Chapter 4}

\section{Results}




\section{COMPUTER-ASSISTED CODING}

The data from the survey questionnaire were analyzed per question, and percentages display the results for each choice selected by respondents from highest to lowest percentage from the most popular answer to the least popular response.

\section{Response Rate of Population}

Out of the 2,600 members of the THIMA community, 75 responded to the survey questionnaire within the three-week time frame.

\section{Profile of Population}

After evaluating the responses from question 10 of the survey questionnaire that asked the respondents to provide their job title, the number of years of coding, and CAC experience, there were 71 out of 75 respondents that answered this question, 4 skipped this question. Out of the 71 that did answer the question, all respondents except 10, listed some type of AHIMA credential starting with RHIT to RHIA, and specialty coding credentials such as CCS, CCS-P, CPC, and CPC-H. There were other credentials listed, such as CCA, CHDA, CDIP, and CCDS. The number of years of coding experience among the respondents was 5 to 36, with an average of 17 years. The number of years of CAC experience was 1 to 15, with an average of 5 years. (see Table 1 below)

\section{Results of Research Questions}

The graphs below were analyzed using Survey Monkey.

Have Claim denials decreased? Most of the respondents, $52 \%$, did not know to answer this question accurately. The difference between no significant change in claim denials and claims denial increased was $1.33 \%$, with no significant change being $21.33 \%$ and increased being 20.00\%. All 75 respondents did answer this question with the results indicating that claims denials overall have not decreased (Graph 1). 
COMPUTER-ASSISTED CODING

Graph 1 - Claim denials have:

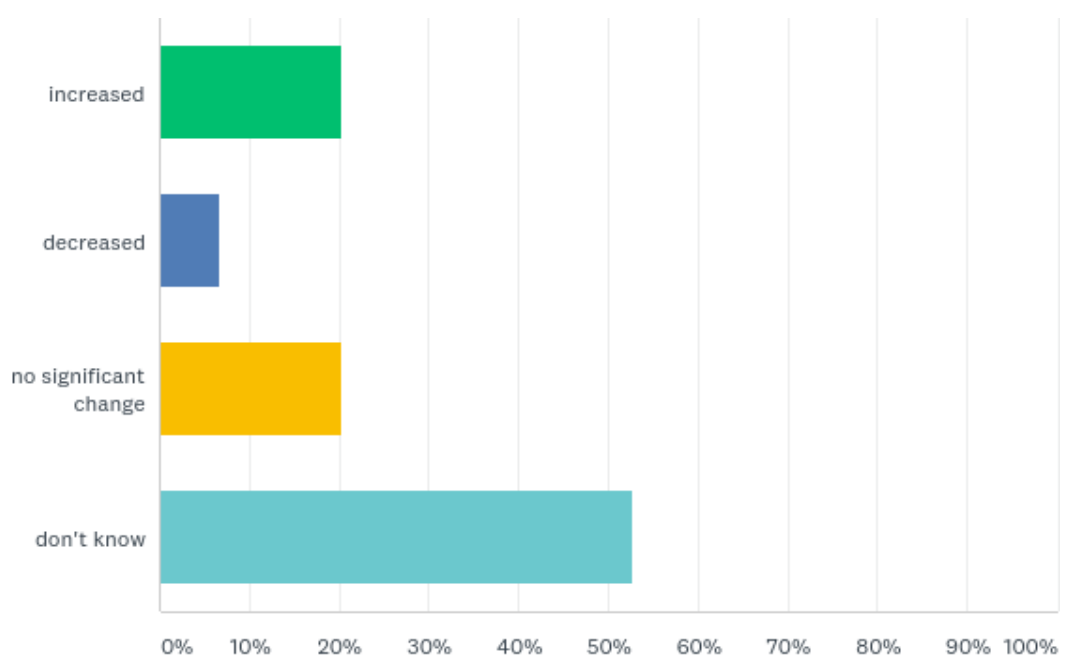

Has consistency and accuracy rates improved? All 75 respondents answered this question with $30.67 \%$ responding, stating that there has been no significant change in accuracy and 28\%, saying that the accuracy rate has increased. The jury is still out about the improvement of consistency since the respondents' responses showed a tie between no significant change and an increase in inconsistency, with each of these answers receiving $20 \%$ of the answers (Graph 2).

Graph 2 - Consistency and accuracy rates have: 
COMPUTER-ASSISTED CODING

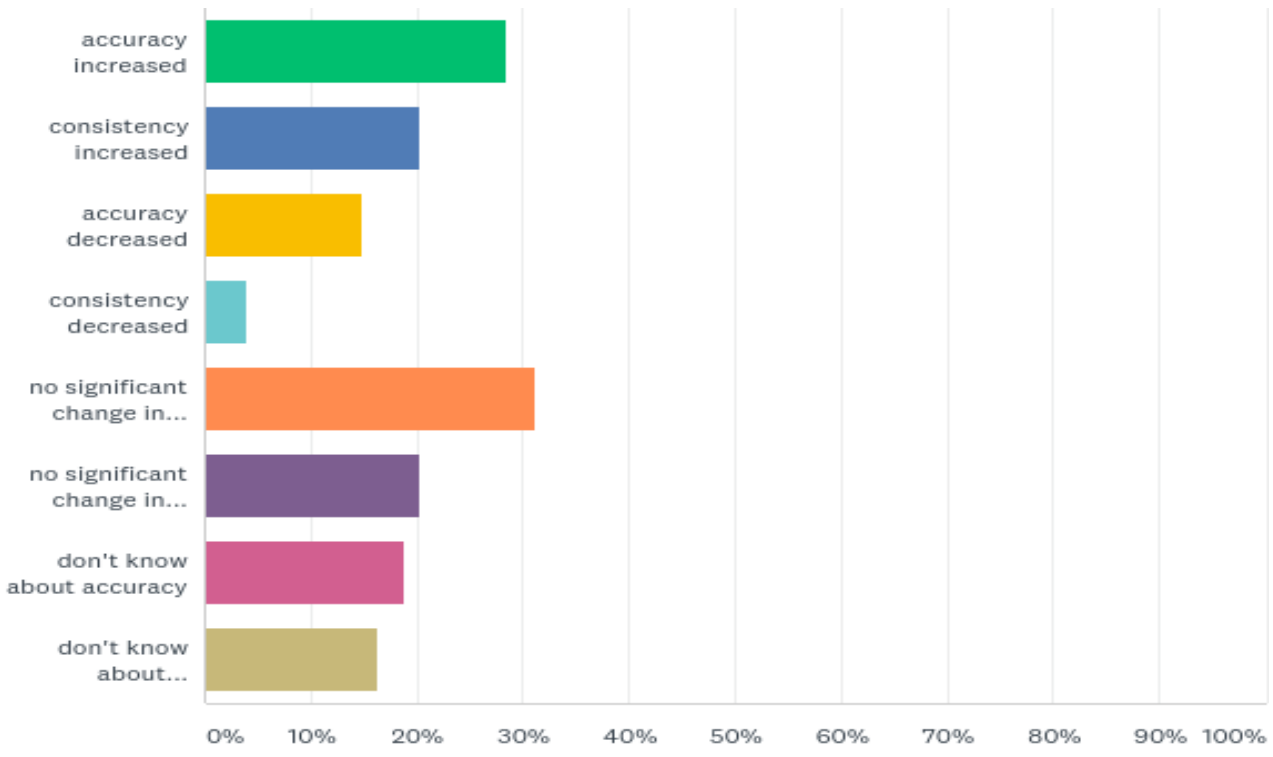

Has coding productivity increased? Only 74 out of the 75 respondents that participated in the survey questionnaire answered this question. Out of those 74 respondents, $33.78 \%$ stated there was no significant change in coding productivity, while $31.08 \%$ indicated that productivity has increased. Twenty-nine percent of the respondents noted that productivity has decreased. Even though most of the respondents thought coding productivity has increased, the percentages for this question are too close to get a definitive statement that $\mathrm{CAC}$ has contributed to increasing the productivity of coding (Graph 3). 


\section{COMPUTER-ASSISTED CODING}

\section{Graph 3 -Coding Productivity has:}

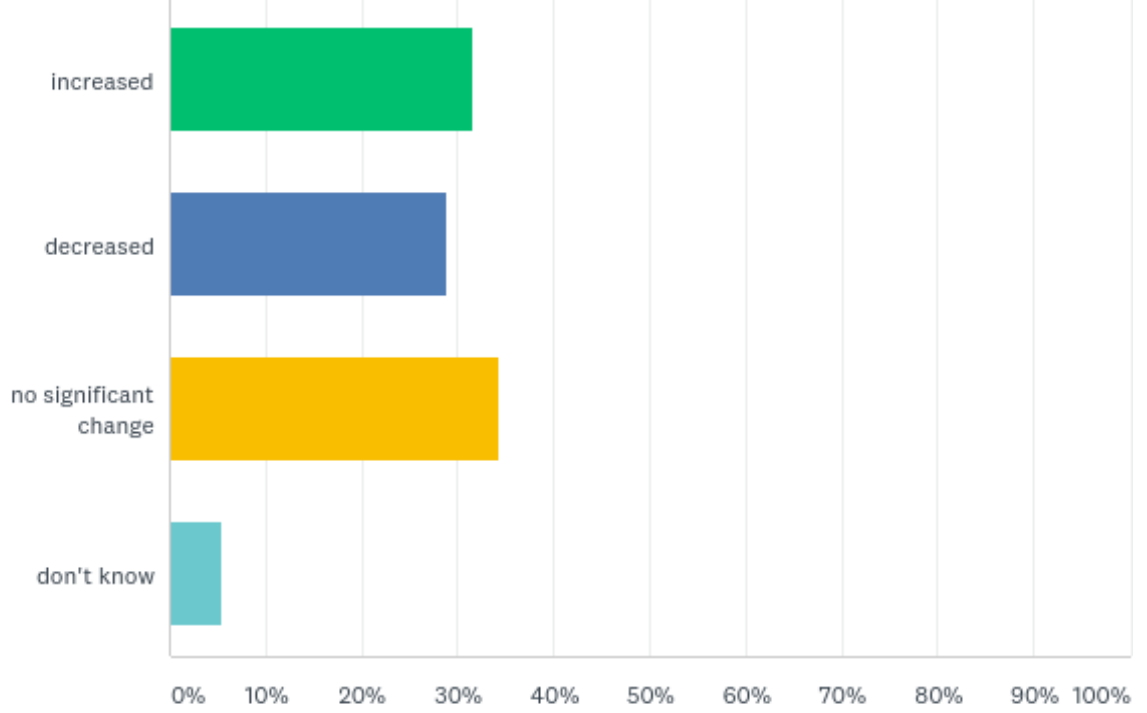

Has the revenue flow increased? All 75 respondents did answer this question with most of the respondents, $25.33 \%$, stating that their facility did not use CAC. There were $22.67 \%$ of the respondents did not know to answer this question with a close $21.33 \%$ saying that revenue increased and $20 \%$ stating no significant change in the revenue flow. There were $10.67 \%$ of the respondents reported that the revenue decreased; this is another question where the responses are too close to get a definitive statement that CAC has contributed to increases the revenue (Graph 4). 
COMPUTER-ASSISTED CODING

Graph 4 - Current Revenue Flow has:

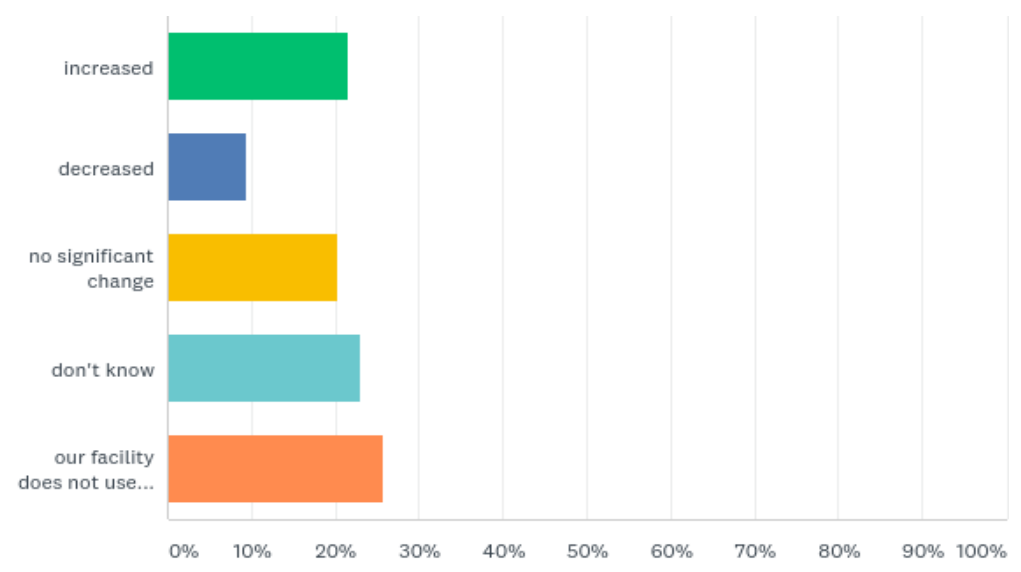

Has CAC resulted in decreasing the number of coders? All 75 respondents did answer this question with an overwhelming $44 \%$ stating that there has been no significant change in the full-time equivalent (FTE) of coders. There was $29.33 \%$ that did not have the knowledge about FTEs to answer the question, and $18.67 \%$ stated that the number of coders has increased (Graph 5). 


\section{COMPUTER-ASSISTED CODING}

Graph 5 -Number of Coders have:

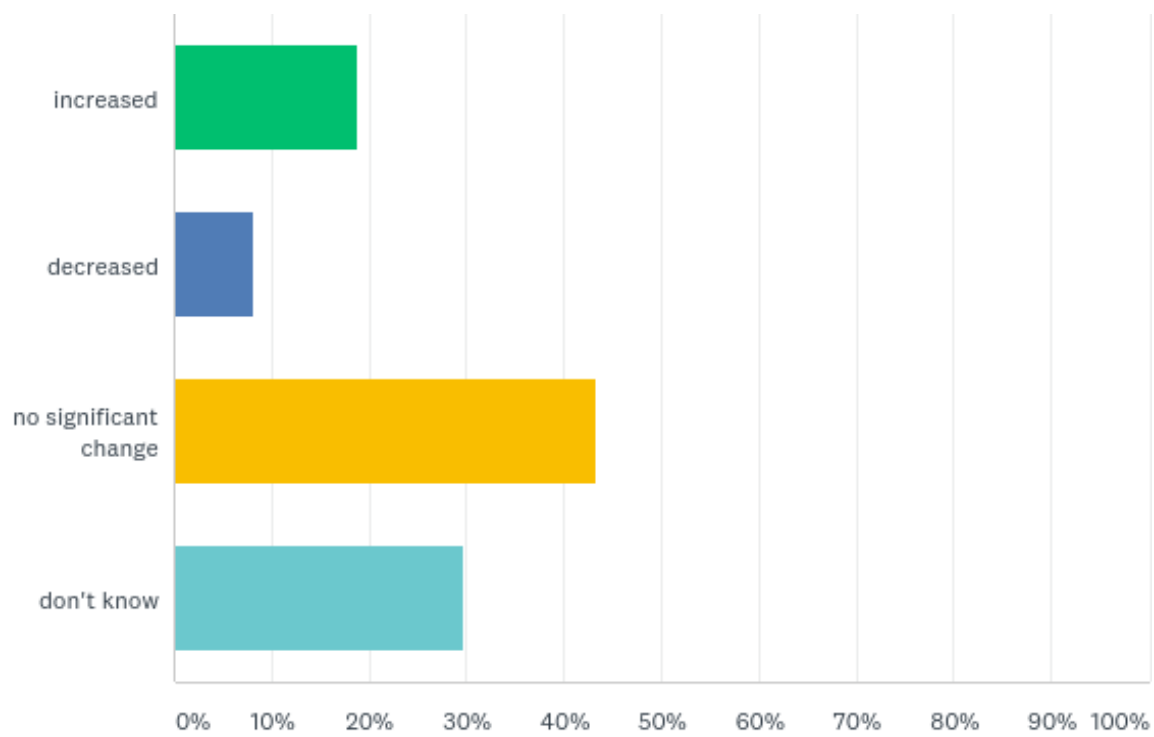

Has the overall coding process improved with CAC? All 75 respondents did answer this question with most of the respondents, $41.33 \%$, stating the overall coding process is satisfactory but still needs improvement. There were $26.67 \%$ of the respondents reported that the coding process is satisfactory (Graph 6).

Graph 6-Overall Coding Process has:

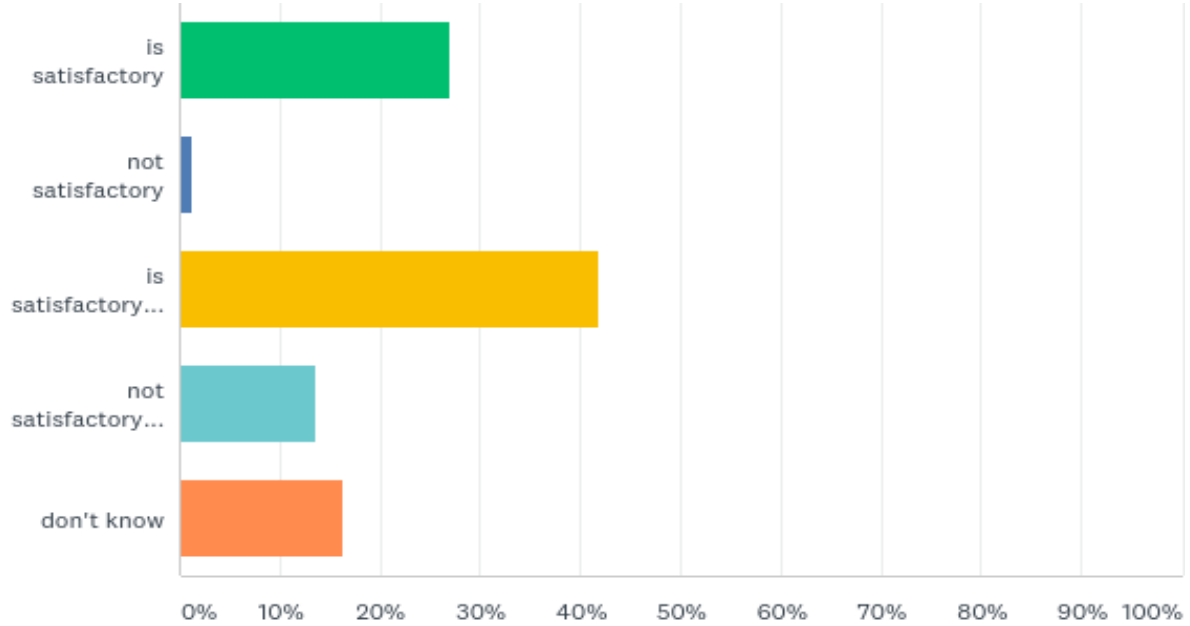


Has clinical documentation improved since the implementation of CAC? All 75 respondents did answer this with $26.67 \%$ stating that CAC has made some improvements in clinical documentation but still needs work. There were $24 \%$ of the respondents that did not have the knowledge to answer this question, and $18.67 \%$ stated that there were no significant improvements in clinical documentation (Graph 7).

\section{Graph 7 - CDI Improvement}

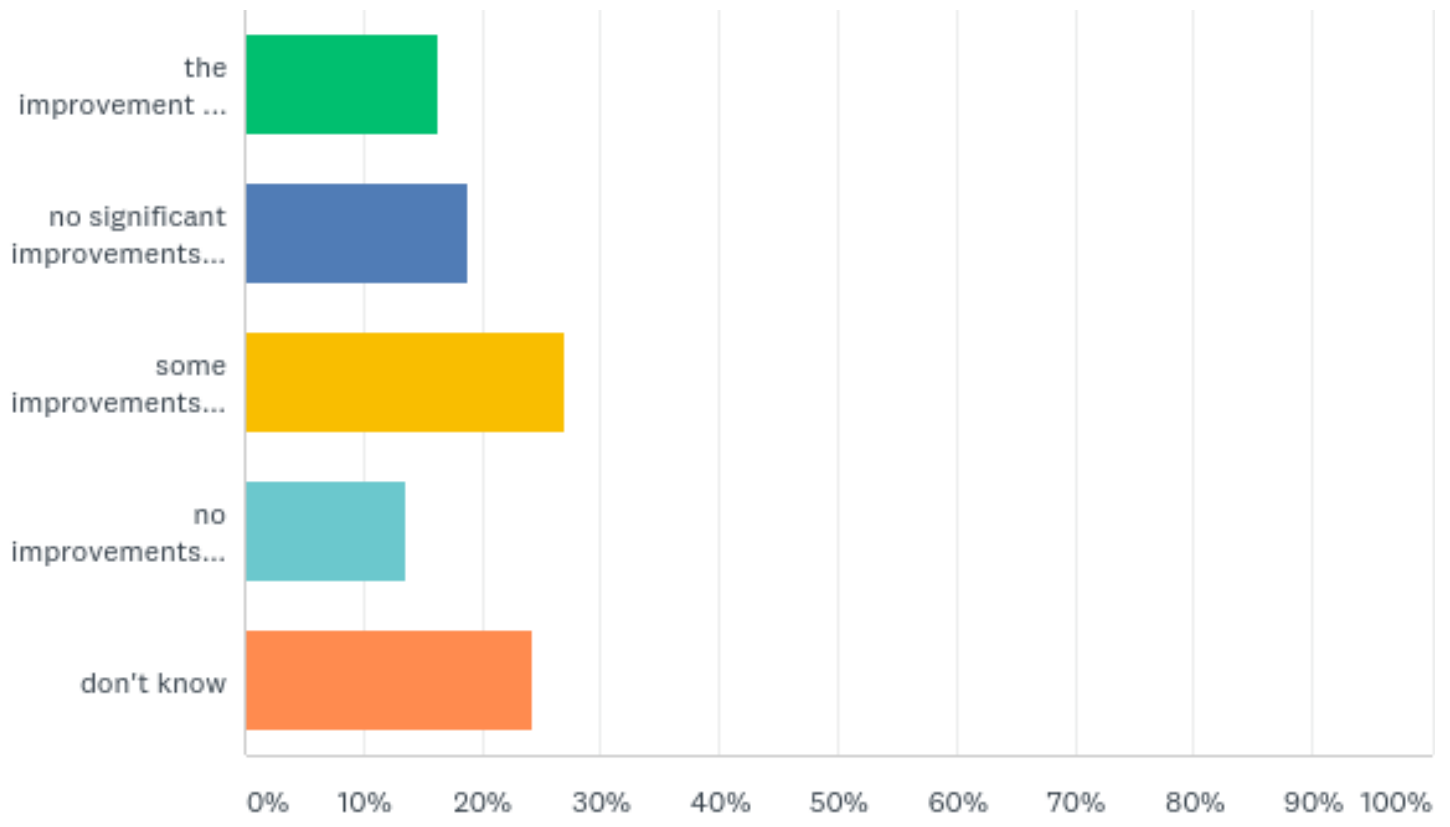

Is it the coders' perspective that $\mathrm{CAC}$ has improved its coding? There were 74 out of 75 respondents that answered this question, with $28.38 \%$ of those respondents stating that CAC has improved their coding accuracy. There were $25.68 \%$ of the respondents agreed that CAC improved their consistency. There was $20.27 \%$ of the respondents that felt CAC hindered their coding, while $18.92 \%$ of the respondents stated that they did not like CAC (Graph 8). 
COMPUTER-ASSISTED CODING

Graph 8-Coders Perception of CAC has:

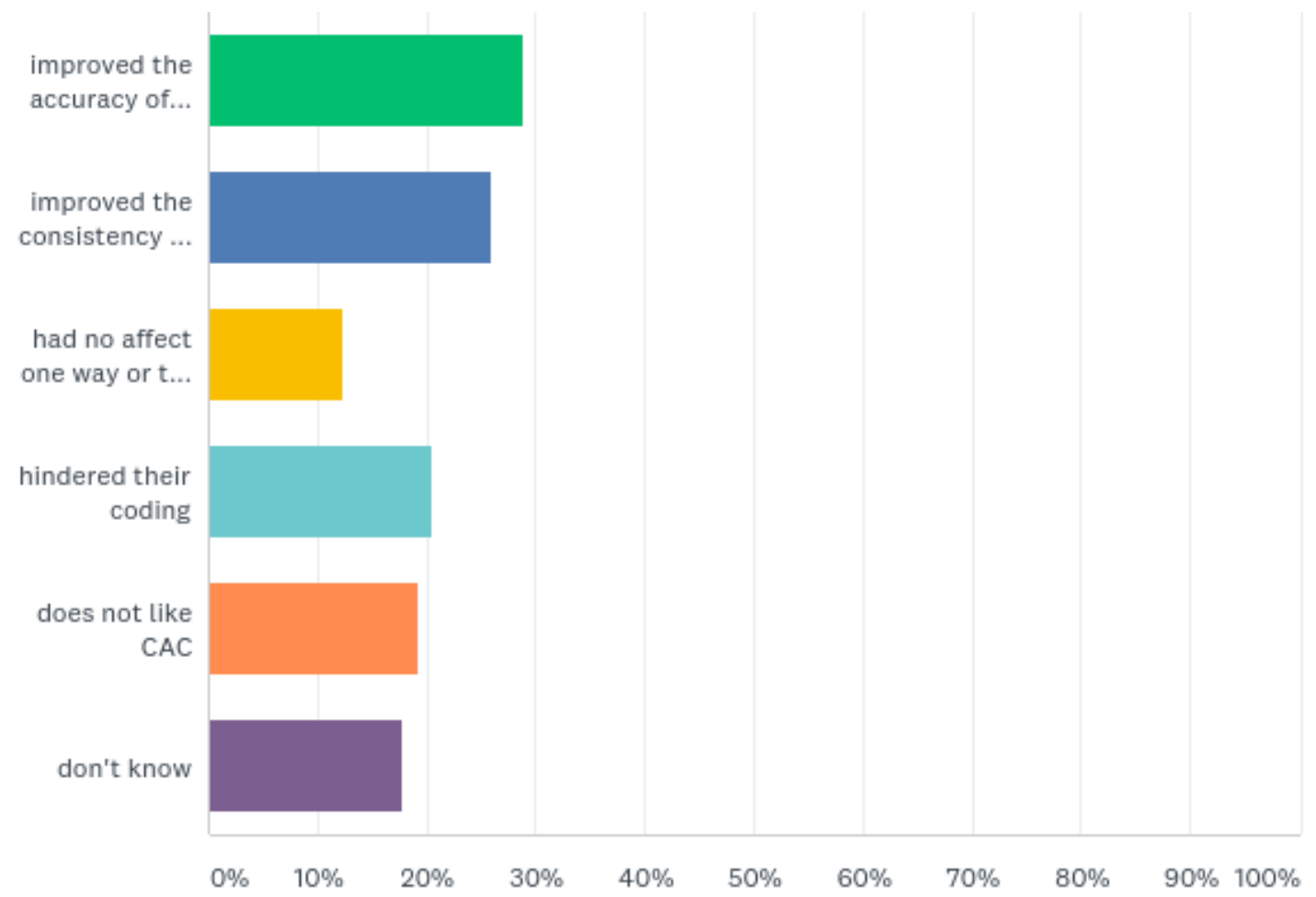

Is CAC a must-have coding software for facilities? All 75 respondents answered this question with an overwhelming $46.67 \%$ that does not think that CAC is a must-have technology for facilities to perform efficiently with their coding. There were $29.33 \%$ of the respondents felt that CAC is a must-have for coding (Graph 9). 
COMPUTER-ASSISTED CODING

Graph 9-CAC is a must-have for facilities

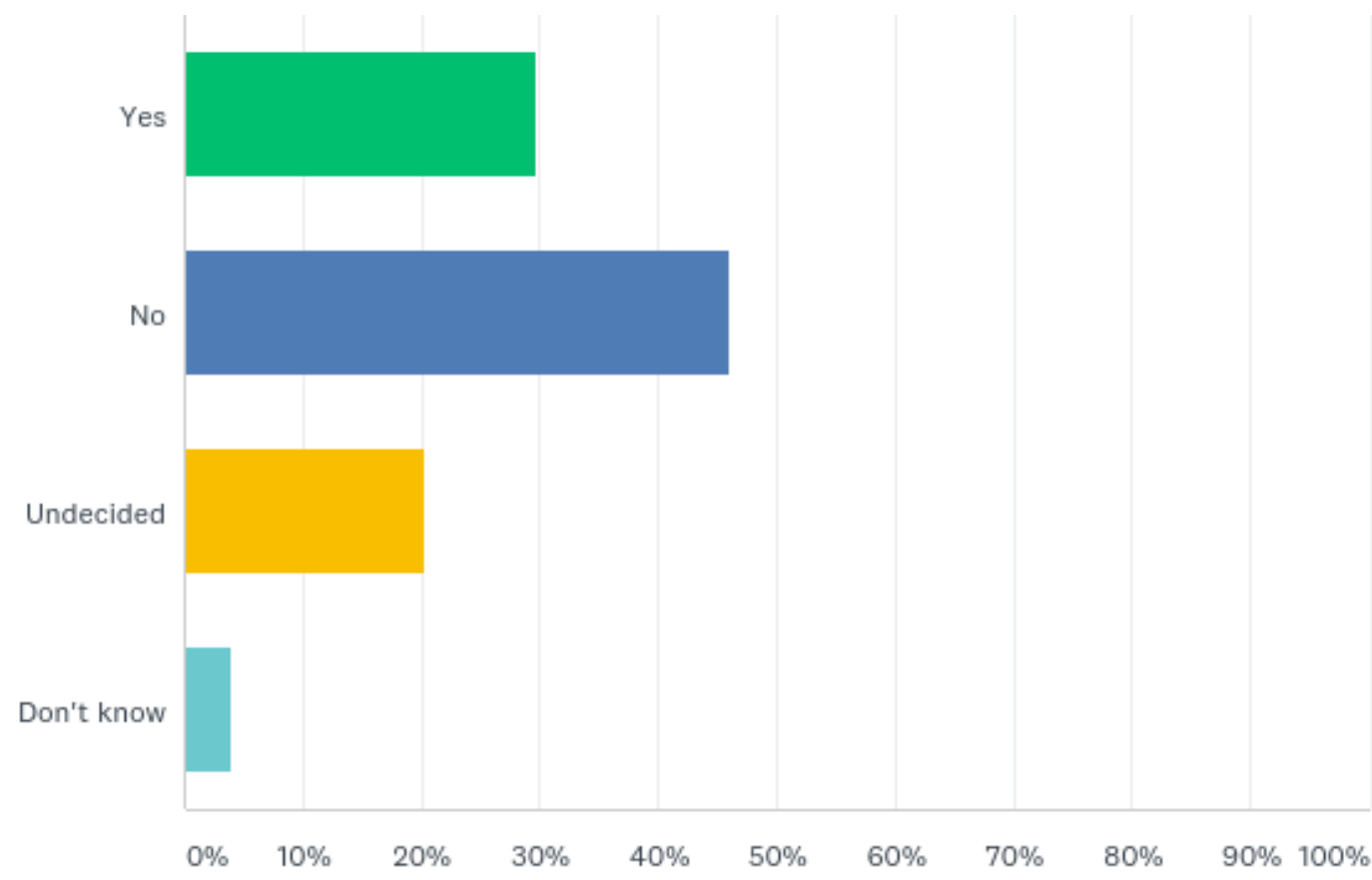

The table below illustrates the answers from respondents about their job title, years of experience with coding, and CAC. This question was included to get an idea of the experience with coding and CAC that the respondents have.

Table 1 - Profile Experience of Respondents

\begin{tabular}{|c|c|c|c|c|}
\hline \multicolumn{5}{|c|}{ Profile of Population } \\
\hline Job Title & Credential & $\begin{array}{c}\text { Years of } \\
\text { Experience } \\
\text { in HIM }\end{array}$ & $\begin{array}{c}\text { Years of } \\
\text { Experience } \\
\text { with Coding }\end{array}$ & $\begin{array}{c}\text { Years of } \\
\text { Experience } \\
\text { with CAC }\end{array}$ \\
\hline $\begin{array}{c}\text { Coding } \\
\text { Integrity } \\
\text { Specialist }\end{array}$ & RHIT, CCS & & 30 & 1 \\
\hline Retired & RHIT & & & \\
\hline
\end{tabular}


COMPUTER-ASSISTED CODING

\begin{tabular}{|c|c|c|c|c|}
\hline $\begin{array}{l}\text { Regulatory } \\
\text { Services } \\
\text { Manager }\end{array}$ & $\begin{array}{l}\text { RHIT, CCS, } \\
\text { CCS-P }\end{array}$ & & 23 & 5 \\
\hline \multicolumn{5}{|l|}{$\begin{array}{l}\text { Client Account } \\
\text { Coder }\end{array}$} \\
\hline Coder & & & 36 & \\
\hline Consultant RN & CCS-P & 11 & & \\
\hline $\begin{array}{c}\text { Inpatient } \\
\text { Medicare } \\
\text { Coder }\end{array}$ & RHIT & & 28 & 3 \\
\hline $\begin{array}{c}\text { Lead IP Coding } \\
\text { Analyst }\end{array}$ & CCS, RHIT & & 5 & 5 \\
\hline $\begin{array}{l}\text { Radiology } \\
\text { Coder }\end{array}$ & RHIT & & 5 & 5 \\
\hline $\begin{array}{c}\text { Coding } \\
\text { Manager }\end{array}$ & CPC, CPMA & & 20 & 15 \\
\hline $\begin{array}{l}\text { Senior Medical } \\
\text { Coder }\end{array}$ & RHIT, CCS-P & & 20 & \\
\hline \multirow[t]{2}{*}{$\begin{array}{l}\text { IP/OutPT } \\
\text { Coder }\end{array}$} & & & 25 & 3 \\
\hline & RHIA & 5 & & \\
\hline Medical Coder & RHIA & & 17 & 5 \\
\hline $\begin{array}{l}\text { Medical Record } \\
\text { Tech }\end{array}$ & RHIT & 9 & & \\
\hline Remote Coder & CCS & & 36 & \\
\hline HCC Coder & RHIT & & 3 & \\
\hline HIM Manager & RHIT & 33.5 & & \\
\hline Coder III & CCS & & 1 & \\
\hline \multirow[t]{2}{*}{$\begin{array}{l}\text { Sr. Coding } \\
\text { Analyst }\end{array}$} & RHIA & 19 & & \\
\hline & RHIT & & 15 & 5 \\
\hline HIM Manager & RHIA & & 1.5 & \\
\hline
\end{tabular}


COMPUTER-ASSISTED CODING

\begin{tabular}{|c|c|c|c|c|}
\hline $\begin{array}{l}\text { Corporate } \\
\text { Coding } \\
\text { Director }\end{array}$ & RHIA & & 32 & \\
\hline Consultant & RHIT, CCS-P & & 20 & Do not like \\
\hline $\begin{array}{c}\text { Coding } \\
\text { Specialist }\end{array}$ & RHIT & & 30 & \\
\hline $\begin{array}{c}\text { Facility } \\
\text { Auditor II }\end{array}$ & $\mathrm{CCS}$ & & 15 & \\
\hline Coder & & & 30 & \\
\hline MD & $\begin{array}{l}\text { CCS, CHDA, } \\
\text { CDIP, }\end{array}$ & & 6 & \\
\hline $\begin{array}{c}\text { Billing } \\
\text { Manager }\end{array}$ & RHIA & 20 & & \\
\hline $\begin{array}{c}\text { Coding } \\
\text { Specialist }\end{array}$ & $\begin{array}{l}\text { RHIT, CCS, } \\
\text { CCS-P, CPC, } \\
\text { CPC-H, CPAR }\end{array}$ & & & \\
\hline $\begin{array}{l}\text { Master INPT } \\
\text { Coder }\end{array}$ & RHIT & & 5 & \\
\hline Coder III & CCS & & 30 & minimal \\
\hline Lead Coder & RHIT, CCS-P & & 20 & \\
\hline INPT Coder & RHIT & & 17 & 5 \\
\hline Coder/Auditor & CCS-P & & 16 & \\
\hline \multirow[t]{2}{*}{ Consultant } & RHIA, CPC & & 10 & \\
\hline & CCA & & 15 & \\
\hline Director HIM & RHIT & & & \\
\hline \multirow[t]{2}{*}{$\begin{array}{c}\text { Coding } \\
\text { Director }\end{array}$} & RHIA, CCS & & 30 & 7 \\
\hline & RHIT, CCS & & 5 & \\
\hline \multirow[t]{2}{*}{ Coder II } & CCS & & 3 & \\
\hline & CCS & & 18 & \\
\hline
\end{tabular}


COMPUTER-ASSISTED CODING

\begin{tabular}{|c|c|c|c|c|}
\hline $\begin{array}{c}\text { Sr Director } \\
\text { Central Coding }\end{array}$ & RHIA, CCS & & 9 & 5.5 \\
\hline \multirow[t]{2}{*}{$\begin{array}{l}\text { HIM Coding } \\
\text { Manager }\end{array}$} & RHIA & & 5 & \\
\hline & CCS & & 6 & \\
\hline $\begin{array}{c}\text { Division } \\
\text { Manager } \\
\text { Coding } \\
\text { Education } \\
\text { Program }\end{array}$ & $\begin{array}{l}\text { RHIA, CHDA, } \\
\text { CDIP, CCS, } \\
\text { CCS-P CCDS }\end{array}$ & & & 9 \\
\hline Manager & RHIT, CCS & & 21 & \\
\hline Medical Coder & RHIA & & 10 & \\
\hline \multicolumn{5}{|l|}{$\begin{array}{l}\text { System Coding } \\
\text { Manager }\end{array}$} \\
\hline $\begin{array}{l}\text { Project } \\
\text { Manager, } \\
\text { Medicare }\end{array}$ & & & 30 & \\
\hline $\begin{array}{l}\text { Trauma } \\
\text { Register }\end{array}$ & & & 3 & 5 \\
\hline \multirow[t]{2}{*}{$\begin{array}{l}\text { Outpatient } \\
\text { Coder }\end{array}$} & RHIT & & 5 & \\
\hline & RHIT & & 30 & \\
\hline Senior Coder & RHIT, CCS & & 28 & \\
\hline HIM Assistant & RHIT & Six months & & \\
\hline Coding Auditor & RHIT & & 2 & \\
\hline $\begin{array}{c}\text { Audit \& } \\
\text { Coding } \\
\text { Specialist }\end{array}$ & CCS & & & 10 \\
\hline $\begin{array}{l}\text { Clinical } \\
\text { Workflow } \\
\text { Analyst }\end{array}$ & & 10 & & \\
\hline Coding Auditor & & & 21 & \\
\hline HIM Director & RHIA & 6 & & \\
\hline
\end{tabular}


COMPUTER-ASSISTED CODING

\begin{tabular}{|c|c|c|c|c|}
\hline $\begin{array}{l}\text { INPT/OUTPT } \\
\text { Coder }\end{array}$ & $\begin{array}{l}\text { RHIA, CCS, } \\
\text { CCS-P }\end{array}$ & & 20 & 6 \\
\hline $\mathbf{R N}$ & $\begin{array}{l}\text { RHIT, CCS, } \\
\text { CRC, CIC, } \\
\text { COC }\end{array}$ & & 15 & $\begin{array}{c}2 \text { (not a fan of } \\
\text { CAC) }\end{array}$ \\
\hline $\begin{array}{l}\text { Director of } \\
\text { HIM }\end{array}$ & RHIT & 2 & & \\
\hline $\begin{array}{l}\text { RAC Audit } \\
\text { Specialist }\end{array}$ & CCS & & 28 & $\begin{array}{l}\text { (I have not } \\
\text { worked at a } \\
\text { facility that } \\
\text { uses CAC) }\end{array}$ \\
\hline $\begin{array}{l}\text { Senior CDI } \\
\text { Auditor }\end{array}$ & $\begin{array}{l}\text { RHIA, CHDA, } \\
\text { CPHI, CCS }\end{array}$ & & 16 & 2 \\
\hline $\begin{array}{c}\text { Coding } \\
\text { Specialist }\end{array}$ & CCS-P & & 11 & \\
\hline $\begin{array}{l}\text { Director HIM/ } \\
\text { Privacy Officer }\end{array}$ & CHPC & & 25 & \\
\hline Director HIM & RHIA & & & 5 \\
\hline \multicolumn{5}{|l|}{ Student } \\
\hline $\begin{array}{c}\text { Coding } \\
\text { Manager }\end{array}$ & RHIA & & & 4 \\
\hline \multirow[t]{3}{*}{$\begin{array}{l}\text { AVP Shared } \\
\text { Coding } \\
\text { Services }\end{array}$} & $\begin{array}{l}\text { RHIA, CHP, } \\
\text { CCS }\end{array}$ & & 24 & \\
\hline & & & $\begin{array}{l}\text { Total years - } \\
\quad 897.5\end{array}$ & $\begin{array}{c}\text { Total years - } \\
107.5\end{array}$ \\
\hline & & & $\begin{array}{c}\text { Average years } \\
17\end{array}$ & $\begin{array}{c}\text { Average years } \\
-5\end{array}$ \\
\hline
\end{tabular}


COMPUTER-ASSISTED CODING

\section{Summary of Chapter}

Most respondents that responded to the survey questionnaire had several years of coding experience but not as many years of experience with CAC. Out of the 75 respondents, the most significant percentage of the answers given felt there was no substantial change in the accuracy and consistency of coding, productivity, and the number of coders employed post-implementation of ICD-10. The conception of the most significant percentage of the coders felt CAC had improved their accuracy and consistency but, there was an overwhelmingly $46.67 \%$ felt that CAC was not a must-have software to perform efficiently with their coding.

Due to the restrictions of the survey questionnaire, some respondents added additional comments in the only open-ended question on the survey, which was question ten. The respondents were asked to list their job title, AHIMA credential(s), and their years of experience in coding and CAC. The additional comments included:

- Not a fan of CAC

- Do not like CAC

- Not a fan at all because they found entirely too many inaccuracies, which causes more work for a coder. Some coders swear by CAC, but I have found that these coders are the ones that just code and do not take the time to ensure the CAC has provided a correct code based on the documentation. 
COMPUTER-ASSISTED CODING

\section{Chapter 5 - Conclusions and Recommendations}

\section{Summary of Findings}

The results of this study reveal that among the respondents that participated, there was a lot of coding experience but not a lot of CAC experience. It was noted that out of the seventy-five respondents, $25.33 \%$ of the facilities where the respondents work, do not use CAC.

This study also revealed that by and large, the overall coding process is satisfactory but still needs improvement with CAC post-ICD-10 implementation. Even though the most significant percentage of respondents felt the accuracy and consistency of their coding had improved with CAC, they did not feel there had been a considerable change. They also noted that CAC is not a must-have technology for facilities to perform their coding efficiently. Also, the study revealed that there had not been any significant difference in productivity, approximately $33.78 \%$, post-ICD-10 implementation. I think it would be relevant here to note that $31.08 \%$ percentage felt the productivity had increased, whereas $29.73 \%$ of the respondents felt productivity had decreased.

\section{Conclusion}

This study was limited to the THIMA community of 2,600 members, with only 75 people participating in the survey. The study revealed that 19 out of the 75 respondents did not use CAC. The study did not overwhelmingly support the use of CAC. The study showed that $46.67 \%$ of the respondents did not feel that CAC was a must-have to perform coding efficiently, and $20.27 \%$ felt that CAC hindered their coding. However, they did agree that CAC improved their coding accuracy and consistency. 


\section{COMPUTER-ASSISTED CODING}

\section{Recommendations}

A more thorough study needs to be done to gather more data to accurately comment on whether CAC has lived up to the hype. Since CAC is expected to grow and reach 4.75 million by 2022, it would be essential to know if CAC is a technology that organizations are going to need to look into for purchasing or for organizations to budget for and use if budgeting becomes a problem. Thirty-five of the seventy-five people surveyed for this study stated that CAC is not a must-have for their coders to code efficiently. Nineteen of the seventy-five respondents say their facility does not use CAC. Although CAC has shown some benefits, this research alone does not indicate that CAC is well established within all organizations, nor has it lived up to the hype. There are many other areas of CAC that should be researched that this study did not cover. This study mainly focused on the highpoints for the reasons for adopting CAC before ICD-10 implementation. This topic needs to be revisited in five years to see if technology has improved the functionality of CAC to convince facilities that this is a must-have technology. 


\section{Rreferences}

AHIMA e-HIM workgroup on computer-assisted coding. (2004). Delving into computerassisted coding. Journal of AHIMA 75, no.10. Retrieved from http://bok.ahima.org/doc?oid=105824\#.Xlp7aUp7mUk

Benson, S. (n.d.). Computer-assisted coding software improves documentation, coding, compliance, and revenue. Perspectives Health Information Management. Retrieved from https://perspectives.ahima.org/computer-assisted-coding-softwareimproves-documentation-coding-compliance-and-revenue/

Boyd, S. \& Paxman, E. (2016). Computer-assisted coding 2016. KLAS. Retrieved from https://klasresearch.com/report/computer-assisted-coding-2016/1111

Brewton, S. (2016). Computer-assisted coding: An auditor's findings. ICD10 Monitor. Retrieved from https://www.icd10monitor.com/computer-assisted-coding-an$\underline{\text { auditor-s-findings }}$

Butler, M. (2019). Computer-assisted coding reality check. Journal of AHIMA 90, no.6: 10-13. Retrieved from http://bok.ahima.org/doc?oid=302747\#.XsbQ8cB7mT8

Campbell, S., \& Giadresco, K. (2019). Computer-assisted clinical coding: A narrative review of the literature on its benefits, limitations, implementation, and impact on clinical coding professionals. Health Information Management Journal. DOI: $10.1177 / 1833358319851305$

Covit, S. (n.d.). Computer-assisted coding - An evolving tool for healthcare. MiraMed. Retrieved from https://www.miramedgs.com/50-focus/pastissues/summer2016/554-computer-assisted-coding-an-evolving-tool-for-healthinformation-management.html 


\section{COMPUTER-ASSISTED CODING}

Despain, J. (2019). Is computer-assisted coding worth the investment? KLAS. Retrieved from https://klasresearch.com/resources/blogs/2019/09/27/is-computer-assistedcoding-worth-the-investment

Dougherty, M., Seabold, S., \& White, S. (2013). The study reveals hard facts on CAC. Journal of AHIMA 84, no. 7: 54-56. Retrieved from https://library.ahima.org/doc?oid=106668\#.Xmb_3Up7mT8

Gue, D. (2014). ICD-10 and computer-assisted coding. Medsphere. Retrieved from https://www.medsphere.com/blog/icd-10-computer-assisted-coding/

Kapit, A., Niv, M., Nossal, M., Resnik, P., Schnitzer, G., Stoner, J., \& Toren, R. (n.d.) Using intrinsic and extrinsic metrics to evaluate accuracy and facilitation in computer-assisted coding. Retrieved from https://pdfs.semanticscholar.org/6b74/584fc708ca77de50c0973f6fd9fdee37fe43.p df

Jimmink, M., Landis, M., Rogers, S., Sheffer, R., Stoyla, C. \& Vernon, M. (2008). Computer-assisted coding at its limits - An analysis of more complex coding scenarios. Perspectives in Health Information Management. Retrieved from https://perspectives.ahima.org/computer-assisted-coding-at-its-limitsan-analysisof-more-complex-coding-scenarios/

LaPointe, J. (2016). Lesson learned from the first year of ICD-10 implementation. Recycle Intelligence. xtelligent Healthcare Media. Retrieved from RevCycleIntelligence.com 


\section{COMPUTER-ASSISTED CODING}

Schnitzer, G. (2008). A coder's perspective on computer-assisted coding software. Radiology Today, vol 9, no. 9, p. 34. Retrieved from https://www.radiologytoday.net/archive/rt050508p34.shtml

Servais, C. (2006). Computer-assisted coding for inpatients - A case study. Perspectives in Health Information Management. Retrieved from https://perspectives.ahima.org/computer-assisted-coding-for-inpatientsa-casestudy/

Stanfill, M.H. (n.d.) Coding professionals' feelings toward computers and automated coding. Perspectives in Health Information Management. Retrieved from https://perspectives.ahima.org/coding-professionals-feelings-toward-computersand-automated-coding/

West, S. (2017). Five years from now: We will still use computer-assisted coding? Streamline Health. Retrieved from https://streamlinehealth.net/HIM-blog/5-yearsnow-will-still-use-computer-assisted-coding/ 


\section{Appendix A - Consent Form}

THE UNIVERSITY OF TENNESSEE

Health Science Center
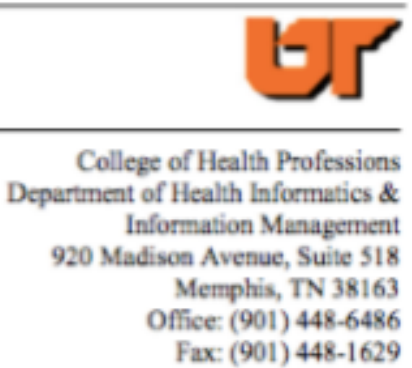

\section{CONSENT DISCLOSURE STATEMENT}

Title of Research: Has Computer-Assisted Coding Lived Up to the Hype?

This is a research survey to address the question, has computer-assisted coding lived up to the hype as previously indicated before the implementation of ICD-10? You can participate in this survey.

I, Teresa Allen, am a student at The University of Tennessee Health Science Center in the Health Informatics and Information Program and, I will be gathering information and analyzing the data received from this survey. This project is being completed under the supervision of Sajeesh Kumar, Ph.D., who can be contacted at skumar10@uthsc.edu or (901) 448-2125. This survey will be posted to the Tennessee Health Information Management Association (THIMA) members and is a product or request from a private individual and not one from THIMA unless expressly noted as such. The information does not represent the views or opinions of THIMA or THIMA membership and is not sponsored or endorsed by THIMA unless otherwise noted.

This survey consists of 10 questions using a Likert Scale that ranges from strongly disagree, disagree, neutral, agree, and strongly agree. It is anticipated that this survey will take approximately 10 minutes, and participation is voluntary. You have the right not to answer any questions and to stop the survey at any point. Identifiable data will not be used in reporting of results, and aggregate data will be used whenever possible. The following measures will be taken to ensure the confidentiality of all data received: no personal data will be collected, including IP address and contact information.

You may contact Cameron Barclay, MSA, UTHSC IRB Director, at 901-448-4824, or visit the IRB website at http://www.uthsc.edu/research/compliance/irb/ if you have any questions about your rights as a research subject, or if you have questions, concerns, or complaints about the research.

Funding for this survey has not been received, and incentives will not be paid to you. Follow-up contact with you concerning the survey will not be made.

Your participation is voluntary, and if you choose not to participate or stop participating at any time, your decision will not result in a penalty or affect your rights. Potential risks 


\section{COMPUTER-ASSISTED CODING}

include tiring from answering questions and loss of confidentiality. There will be no direct benefits for you in this survey, but the knowledge gained will provide valuable information as to the benefit or not of computer-assisted coding.

Information gathered for this study is the result of a survey tool posted by Teresa Allen. If there are questions pertaining to this survey, please contact Teresa Allen at (615) 230 3766 or teresa.allen@volstate.edu.

Thank you,

Teresa Allen

Resource: University of Tennessee Health Science Center 
COMPUTER-ASSISTED CODING

\section{Appendix B - Survey Questionnaire}

\section{Computer-Assisted Coding Survey Questions}

The purpose of this research/survey is to gather the latest data about the effectiveness of computer-assisted coding.

1. Post ICD-10 implementation how well does the following statement describe the current process of claim denials at your facility. Claim denials have:

- increased

- decreased

- no significant change

- do not know

2. Post ICD-10 implementation, how well does the following statement describe the current overall accuracy and consistency rates of coders at your facility? The accuracy and consistency rates have:

- accuracy increased

- consistency increased

- accuracy decreased

- consistency decreased

- no significant change with accuracy

- no significant difference with consistency

- do not know about the accuracy

- do not know about consistency

3. Post ICD-10 implementation, how well does the following statement currently describe the productivity of coding at your facility? Coding productivity has:

- increased

- decreased

- no significant change

- do not know

4. Post ICD-10 implementation, how well does the following statement describe the current effects CAC coding has had on the revenue flow at your facility? The current revenue flow has:

- increased

- decreased

- no significant change

- do not know

- our facility does not use CAC 
5. Post ICD-10 implementation, how well does the following statement describe the current coding cost/FTEs at your facility? Coding cost/the number of coders have:

- increased

- decreased

- no significant change

- do not know

6. Post ICD-10 implementation, how well does the following statement currently describe the overall coding process using the computer-assisted coding at your facility? The overall coding process:

- the coding process is satisfactory

- not satisfactory

- the coding process is satisfactory but still needs improvement

- not satisfactory and needs much improvement

- do not know

7. Post ICD-10 implementation, how well does the following statement currently describe clinical documentation (CDI)? CAC has contributed to:

- the improvement of clinical documentation

- no significant improvements in clinical documentation

- some improvements but still needs work

- no improvements at all

- do not know

8. Post ICD-10 implementation, how well does the following statement currently describe the acceptance of CAC by the coders? Coders feel CAC has:

- improved the accuracy of their coding

- improved the consistency of their coding

- did not affect one way or the other on their coding

- hindered their coding

- does not like CAC

- do not know

9. Post ICD-10 implementation, in your opinion, do you feel that CAC is a musthave for facilities to perform efficiently with their coding?

- Yes

- No

- Undecided 


\section{COMPUTER-ASSISTED CODING}

- do not know

10. Please provide your job title, AHIMA credentials, if any, and the number of years of experience you have had with CAC and coding. 